\title{
Electronic publication and submission of papers by floppy disk or email begin
}

The year 1995 brings us to volume 49 of the JECH. The year will be the the time for preparing for our jubilee volume (volume 50 ) aimed at celebrating the expansion of social and preventive medicine and epidemiology in Britain, North America, and Europe.

But 1995 will also have important developments of its own. Several supplements will be published with papers from throughout Europe and we propose to take a major step into electronic publishing, initially by means of electronic networks.

The form of electronic publishing will enable us to publish supplementary material for articles which would otherwise be too long (or have too much tabular data) and to publish conference abstracts easily and quickly. For a selected group of papers it will also enable us to increase the number published and give us a shorter time from acceptance to publication. The proposal is that the electronically published material will be indexed as usual in the journal itself and also, we hope, in the abstracting services.

Authors will be advised in the near future about the details which will be linked to submission of papers on floppy disks or by email. In all these cases some graphic presentations may cause difficulties but tables of data should be no problem.

\section{In this number}

Our wide geographical spread of papers continues, including information from the former Eastern bloc. Several papers including one from the large US nurses study consider further evidence about the relationship of early life experiences to heart and other diseases in adulthood. Various aspects of screening for cancer and other illnesses are covered, together with consideration of instruments for surveying health and well-being as perceived by individual people.

Our Editorial continues the debate in this and other journals about the philosophy and value of health promotion. Across Europe there can be few more pertinent questions than those about the opportunity costs of various interventions aimed at promoting health and welfare. Professor Kelleher, a member of our Editorial Board, refers to the so-called Mad Hatter's Tea Party (from the book Alice in Wonderland) which may not be very familiar to colleagues who did not grow up with middle class English children's books! The idea is that individuals as different as a dormouse, a white rabbit, a hat-maker ("mad" from mercury poisoning) and Alice (in Wonderland) can sit and talk together (at the tea table) but achieve nothing-not even proper communication - because of vastly differing modes of thought and perception. Good luck with the rest of the story!

\section{Health promotion: shades of Lewis Carroll}

\section{Public health policy}

The promotion of health is increasingly being adopted into public health policy in countries around the European region. There are now several examples of countries where proactive approaches have been considered on the lines of the World Health Organization's strategy, Health for all by the year 2000. The United Kingdom's Health of the Nation emphasises specific targets based around population changes in traditional risk factors for coronary heart disease, accidents, and cancers. ${ }^{1}$ Within my own country, Ireland, the National Department of Health has produced this year a document entitled Shaping a Healthier Future which advocates measurement of health services in terms of health gain and social gain. ${ }^{2}$ There is a renewed emphasis on primary care; reoriented proactive services generally and health promotion strategies appear in virtually every aspect of health care delivery. Later this year a more detailed health promotion strategy is expected. Its contents are unknown but it is likely to maintain the emphasis on cross sectoral responsibility for health that has been a 
principle of health policy in Ireland for the past seven years.

Increasingly, the World Health Organization has sponsored initiatives in various countries that have shifted the focus deliberately from lifestyle fixated individualistic strategies to social and environmental change in order to create supportive environments. Examples of these include programmes for the school, the workplace, the hospital, and the city. The European Union has also taken the initiative in that the Maastricht treaty finally explicitly recognises public health as a legitimate policy issue, thus opening the way for funding and support between member states. This revision of health policy as a response to chronic disease epidemics is a feature of developed countries generally. The United States, for long the home of a model of health promotion that focusses on individual, responsible lifestyle change is also in the course of serious debate about the organisation and funding of its mammoth and fragmented health care delivery network.

In the face of this very real sea change, it is ironic that controversy continues to surround the very fundamentals of health promotion. Public policy reflects, to some degree, theoretical knowledge bases, and in the case of health promotion evidence has been provided from a spectrum of social science and biomedical disciplines. Policy shift on this basis has not been without its detractors. What is not sufficiently appreciated is that there are certainly more than two sides to the debate so that proponents and critics of health promotion do not always automatically line up on the same team for every issue.

\section{Four problems with health promotion}

There are four basic problem areas that people have with health promotion. These are exhibited in both the scientific and lay literature and are reflected in the policies advocated in different countries and regions. The four areas of controversy may be defined as observational scientific, experimental scientific, pragmatic, and moral. It is not uncommon to argue a problem on the basis of one issue because of views from another perspective. At various times and even within the same article, arguments can be marshalled to one purpose and interpreted for another.

\section{Observational "science" and public policy}

The observational scientific school of thought concerns the different disciplinary approaches to so-called determinants of health and illness. In other words, what keeps us well or makes us sick? This latter is, of course, traditionally the epidemiologist's territory. We have accumulated a vast and, by no means, homogenous database on determinants of various disease processes. This has been successful to a point in that it has provided a rich and fascinating pattern to unravel. In order to make progress with what is essentially a reductionist model, however, we have had, firstly, to rely on traditional biomedical paradigms and, secondly to make quantitative mathematical assumptions about the bio-psycho-social interrelationships we were attempting to discriminate one from the other. The research skills that will be exercised in the further development of epidemiologyy in the next years are acutely important and exciting. This certainly includes development of qualitative measurement tools.

Conjecture about basic scientific issues is an imperative part of the pursuit of human knowledge and is rightly an end in itself. It is where such arguments are used as the basis of staying public policy that concern is raised. For instance, continuing controversy about diet and coronary heart disease provides a good example. It is true that we do not have all the answers about the aetiology of this complex multifactorial disease but we do know a great deal. Is action on the basis of what we do know a matter of imprecision or of real systematic error that could adversely affect the public health? Public health guidelines, as opposed to guidelines for specific individual management, are all broadly in agreement on advice to eat a balanced diet, take more exercise, and reduce the relative fat intake in favour of fruits and vegetables. While these may be argued as vague or aspirational by some, it is unlikely from any known evidence that qualitative advice of this kind could translate into a nutritional catastrophe. The scientist contributes precision to this message but the gist of it has simply not been refuted over a quarter of a century of epidemiological study. What needs to be resolved about basic scientific arguments on any issue, health promotion or not, is at what point can action be taken to translate existing knowledge into policy and whose responsibility is it to take the consequences of that decision in either eventuality?

\section{Applied science and implementation}

The applied scientific arguments are essentially based around the success or otherwise of interventions designed to modify the environment or individual behaviours. Consistently, these arguments are constructed around the assumption that change must be measurable if it is able to occur. This may on occasion be spurious reasoning because it depends on the sensitivity of our current tools of measurement. It is our responsibility to set up any experiment properly and all we can ask is whether the anticipated outcome occurs or not. When it does not occur, we state that our null hypothesis has not been refuted rather than that it has been proved. For example, secular lifestyle changes that correlate with mortality trends occur in a community intervention site and also in a control or reference area, therefore the experimental region was not demonstrably different. Where does that leave us? Well, firstly it could mean that the experiment as intended was a failure. It could mean that the experiment as executed was a failure because it was not feasible within the time frame and resources. It could also mean that the experiment was a success in an unanticipated way - that is, through contamination of the reference areas). It could mean that in some respects the experimental area will show more subtle health gains over a longer period of time so that further follow up will show a difference. It could mean that the health gains in both areas are coincidental due to as yet unmeasured confounding factors in both situations, and it is interesting how enthusiastically epidemiologists adopt this one. The final, and usually least considered explanation is that the processes leading to the establishment of the experiment were not conceived in a vacuum but reflect the far more sophisticated reality of human society than any social experiment yet devised. In other words, the integration of the observational epidemiological evidence into the local culture is occurring, albeit in a diffuse haphazard but effective manner, at the same time as the more formal intervention. Life imitates art so why not science? What is common to all these situations is the critical need for proper measurement tools.

What are the policy makers to make of all this? In England, at least, the message of health promotion has been very incompletely assimilated. Arguably, the whole health promotion process has been effectively focussed into two sectors, as preventive medicine in the National Health Service and to a lesser extent as health education in the education sector. There has been concern that essentially cosmetic programmes, which could not hope to be effective, might damage the credibility of health promotion generally and this is happening to some 
extent. When the family heart study of a general practice intervention was published recently it was widely interpreted as proof that health promotion does not work. $^{3}$ In fact it showed several important findings; firstly, that the intervention did work, though in a more modest way than anticipated. Secondly, the authors cautioned that in the light of their more intensive intervention, with its modest gains, the existing policy in general practices was too cosmetic to achieve even this effect and that many more resources would be required. Thirdly, directly in line with any health promotion policy advocated since the Ottawa Charter in $1986,{ }^{4}$ the paper underlines that such essentially clinical activities cannot be conducted in a vacuum and that there must be wider public policy initiatives to achieve health goals. The evaluation of two school smoking education programmes under normal classroom conditions two years ago implied the same conclusion. ${ }^{5}$ The point? If we want to evaluate health promotion activities, we need not only robust methods of evaluation, but robust interventions to evaluate. We also need to plan the intervention against the wider environment in which it is to be conducted. Logically therefore comparative interventions in either the health or education sector should be evaluated as relative contributors to health promotion and should focus more specifically on process rather than outcome measures. If we want to know precisely how or whether personal skills development or preventive medicine services influence either smoking uptake or cessation, then these interventions should probably follow rather than precede more comprehensive social reform. This is an important matter for debate.

\section{Economies and opportunity costs}

Then there is the pragmatic or economic argument, which basically makes the point that health promotion activities are an unnecessary resource diversion in times of cost constraints. How can we afford to spend money on these "soft" activities when there are so many more pressing priorities? The issue here is what precisely the opportunity cost in question is. I might, for instance, as Nancy Milio has persuasively done, compare a health education policy on nutrition, which essentially lays all the responsibility at the door of the individual, with an agricultural policy on food production which facilitates appropriate food supplies. ${ }^{6}$ In this manner, a proper attempt at economic analysis might be mounted. The inappropriate comparison is between a nutrition policy of any kind and a hospital facility to treat chronic disease. In this instance the competing interventions cannot be compared in the same time frame, let alone on the same terms.

It has been seriously debated that in medicine many routine treatments have either never been proved effective or, if they have, are being applied too late and on an absurd scale. Arguing for a moment that this is so, what therefore accounts for their prevalence and popularity? This is where social attitudes become critical. Because public expectation is predicated on the availability of such services in the belief of their appropriateness, that is where the pressure for resources is. Once there is a fundamental commitment to proactive health policies, which implies a shift in those attitudes on behalf of the relevant professionals and the people they serve, then in time the operative budgets will follow. Meanwhile, the pragmatist is not value neutral, in fact, but may be in defence of a prevailing paradigm that is no more robustly rooted than the newer idea.

\section{Moral dimensions}

Finally, and most fundamentally, comes the moral ar- gument. A recent article in this journal reminded us that motivation regarding public policy on health matters is also not value-neutral. ${ }^{7}$ The Third Reich was an early proponent of health promotion activities, particularly in relation to smoking. (It is important incidentally to be reminded of the potential power of propaganda and indeed Goebbels is famous in media circles for his fundamental recognition of entertainnent as a key element. Sadly, health education material is often in no danger of subverting the masses because it is not always primarily entertaining and is produced on a minuscule budget, but this aspect is rarely examined in evaluations either.) To juxtapose enthusiastic, ineffective health promotion activities with grotesque inhumanity is a neat example of the double purpose argument. Petr Skrabanek, in his recently published book, reminds us (with the apparent implication of association) that many sadistic and brutal regimes have been signatories at times to documents like the WHO Health for all strategy. ${ }^{8}$ The Third Reich was essentially a profoundly evil system and as such represented a gross abuse of power. The world did not go to war about Hitler's smoking policies or even his motivation for his smoking policies. We cannot say that all social change policies are evil or wrongheaded generally just because some such policies are. Whenever there are collected groups of people, there will be a development of public policy to regulate their activities. Modern day Germans may arguably associate social change policies in general, and about smoking in particular, with a past era of totalitarianism, as the authors imply, ${ }^{7}$ but this in no way challenges either the legitimacy of promoting health protection in public policy now, nor indeed of examining lifestyle behaviour in this context. The article tackles a completely different issue in examining the effectiveness of interventions. To say that smoking rates continued to rise in the face of a short term curtailment is not necessarily proof of the failure of an anti-smoking policy. For instance, changes in smoking rates have always been associated with wars because of improved distribution of the product, among other things.

When does healthy public policy work as opposed to individual personal skills development? In health promotion terms you cannot really have the one without the other if it is to be described as enabling. Compliance is not exclusively a matter of exercising prohibition. We have rules of the road because we agree in principle with the need to predict each others' activity on the highways. Most of the time, however, we co-exist in this consenting process with a flagrant subculture of minor violations. To the Martian this may be a paradoxical state of affairs but to even a modestly competent sociologist, let alone the layman, it is perfectly comprehensible. The fact is that smoking policy, to work, most certainly needs the social consent of the majority and must fit into a more subtle regime of support. This is why personal skills development, regulation of public smoking, controls on advertising and financial measures are all part of the issue.

What about the "busybody" argument, first mooted by the ancient Greeks? For every pompous King Canute who thinks he is ordering the waves, there is also a variety of lesser busybodies on the beach, collecting litter, prohibiting nudists, ticking off people, with defecating dogs. The fact is that virtually no-one minds his own business in any case, and we decide our acceptance of the intrusion, not solely on the principle that it is an intrusion but on whether it is appropriate or beneficial. How far could or should health promotion go? The spectrum extends from those who advocate no 
intervention, to those who pursue the issue to the extreme limit of social control. Indeed, social policy is increasingly examining issues not just of whether, but how we might justly intervene in areas of social need so that the intervention is enabling for the many people in our societies who are alienated. ${ }^{8}$

\section{Cross purposes, directions, and tolerating the status} quo

Meanwhile we find a situation not unlike Lewis Carroll's tea party where the unlikeliest of allies conduct arguments at cross purposes, though in apparent harmony. The individual who advocates punitive physical fitness as a health measure may find followers among the leisured and affluent middle classes. These have little in common with the Marxist advocate of social reform to standardise living conditions between the social classes. Neither will have much in common with the liberal supporter of freedom of choice to enable true personal control of one's health, and all three will be perplexed by the spiritually motivated individual who sees health as futile unless it is synonymous with spiritual wellbeing, even at the price of the physical.

An American paper recently cautioned against the tyranny of health - meaning by this the prevailing obsession with personal lifestyle modification and the expectations inherent from it. ${ }^{10}$ Healthism is primarily a neurotic process, however, and is not necessarily a health promotion activity. We do need to prioritise our value systems in relation to health. There is a real need to address the unrealistic expectations of many people from lifestyle change. We cannot hope to live forever, rather to delay death for most people by a few years and to alleviate the burden of disease and disability. Further, we need to assess more profoundly the spiritual vacuum that a preoccupation with immortality apparently reflects. Population strategies will mean small health gains for most people rather than large gains for some. Uncle Norman, far from being a perplexing figure for epidemiologists, is in fact the exceptional survivor who proves the population rule.

At the moment, our policy priorities have got as far as the reduction of premature mortality, and we give lip service at least to the reduction of social inequality and inequity. To tackle social inequality as a humane objective is one issue, it must also be considered a priority for health promotion. If we started to see lifestyle as one sign of health inequality rather than exclusively a determinant in itself, we might make more progress. For the medical profession, a principle of its own needs examining; Primum non nocere is essentially a clinical instruction cautioning against errors of commission. Increasingly, there is need to examine the responsibility for errors of omission as well. Skrabanek also recently stated that medicine is not about conquering diseases and death but about the alleviation of suffering, minimising harm, smoothing the painful journey of man to the grave ${ }^{8}$. Medicine, he said, has no mandate to be meddlesome in the lives of those who do not need it. Was he right? It would be much easier for us all if he were because we would not need to contemplate any real shift from clinical medicine, but the evidence does not support this fatalistic predeterminism. Disease, discomfort, and human misery are variables not constants, as are wellness and happiness, so we must do something to address why.

Where then should health promotion be headed? If there is a core discipline to health promotion it is an applied one, which needs the range of academic expertise to examine and enlighten any of the four areas discussed in this paper. The need to establish more firmly a theoretical commonality does not necessarily have to stem public policy initiatives for the betterment of public health. Those governments that have been persuaded this far are to be applauded for their vision. The observational evidence provides guidelines for public policy that can be acted upon. Though undoubtedly there is need to continue to refine methodologies in measurement of health and illness, there is no reason why we cannot prioritise traditional risk factors and diseases as markers for success in health gain. After all, these are measurable and understandable. Changes are needed and can be achieved but we cannot go on using exclusively biomedical approaches to the actual interventions. The issue of interventions is more complex in that we have not given sufficient thought to what we are evaluating. What we can do is to stem interventions that are too cosmetic to achieve the desired effects and, if necessary, advocate more focussed comparative studies. We should start to debate the ethical dilemmas more robustly but not from the prevailing position that assumes the status quo is more morally defensible because scientists had no hand in making it that way.

Often it is the silence of the sceptic that condemns as cogently as the shout of the fanatic.

Department of Health Promotion,

Clinical Science Institute,

University College Galway,

Ireland

Member of $\mathcal{F E C H}$ Editorial Board

CECILY KELLEHER

1 Department of Health. The Health of the nation: a strategy for health in England. London: HMSO 1992.

2 Department of Health. Shaping a healthier future. A strategy for effective healthcare in the 1990s. Dublin: Stationery Office. Government Publications. 1994.

3 Family Heart Health Group. Randomised controlled trial evaluating cardiovascular screening and intervention in general practice: principal results vascular screening and intervention in general practice

4 of British family heart study. BMf 1994;308:313-21.

4 World Health Organisation. The Ottawa charter. Health Promotion 1986;1:4. Nutbeam D, Macaskill P, Smith C, Simpson JM, Catford J. Evaluation of two school smoking education prog

6 Milio N. Promoting health through public policy. Ottawa: Canadian Public Health Association, 1986.

7 Davey Smith G, Strobele SA, Egger M. Smoking and health promotion in Nazi Germany. $\mathcal{F}$ Epidemiol Community Health 1994;48:220-4.

8 Skrabanek P. The death of humane medicine and the rise of coercive healthism The Social Affairs Unit. London. 1994.

9 Williams F. Social policy: A critical introduction. Blackwell Publishers: Cambridge, 1989.

10 Fitzgerald FT. The tyranny of health. New Engl f Med 1994;331:196-9. 